\title{
The Conserved TFLK Motif of Mammary-Associated Serum Amyloid A3 Is Responsible for Up-regulation of Intestinal MUC3 Mucin Expression In Vitro
}

\author{
DAVID R. MACK, THOMAS L. MCDONALD, MARILYNN A. LARSON, SHU WEI, AND \\ ANNIKA WEBER \\ Department of Pediatrics, Children's Hospital of Eastern Ontario and University of Ottawa, Ottawa, \\ Ontario, Canada [D.R.M.]; Departments of Pediatrics [D.R.M., S.W.] and Pathology/Microbiology \\ [T.L.M., M.L., A.W.), University of Nebraska Medical Center, Omaha, Nebraska, U.S.A.
}

\begin{abstract}
In various mammalian species, an isoform of serum amyloid $\mathrm{A}$ is secreted at high concentrations into colostrum. A conserved four-amino-acid motif (TFLK) is contained within the first eight $\mathrm{N}$-terminal amino acid residues of this mammary-associated serum amyloid A isoform 3 (M-SAA3). Peptides derived from the bovine $N$-terminal amino acid sequence of M-SAA3 were produced and added to cell culture medium of HT29 cells to study the effects on intestinal mucin gene expression. HT29 cells were grown to enhance expression of either MUC2 or MUC3 intestinal mucins. After incubation, total RNA was isolated for Northern blot analyses using MUC2 or MUC3 mucin cDNA probes. Signals were detected by autoradiography with mRNA levels expressed relative to $28 \mathrm{~S}$ rRNA. The 10 -mer peptides containing the intact TFLK-motif or a TFLK 4-mer peptide increased MUC3 mRNA expression compared with control cells $(p<0.05)$. There was no effect of these peptides on MUC2 mRNA expression. Cells that were incubated with 10-mer $\mathrm{N}$ terminal derived peptides containing a scrambled TFLK motif, with all 10 amino acid residues scrambled or derived from a
\end{abstract}

\section{ABSTRACT}

C-terminal region of M-SAA3, did not show increased MUC3 expression. Inhibition of enteropathogenic Escherichia coli strain E2348/69 adhesion to HT29 cells grown to enhance MUC3 expression was reduced by a similar amount when either peptides containing the intact TFLK motif or probiotic microbes were added to cell culture medium compared with control cells. M-SAA3 is a bioactive peptide secreted into colostrums that can up-regulate mucin expression and thereby may enhance innate protective mechanisms that limit access of deleterious microbes to intestinal mucosal epithelial cells in the postparturition period. (Pediatr Res 53: 137-142, 2003)

SAA, serum amyloid A

\section{Abbreviations}

SAA3, serum amyloid A isoform 3

A-SAA, acute phase serum amyloid A

M-SAA3, mammary-associated serum amyloid A isoform 3

EPEC, enteropathogenic Escherichia coli

CFU, colony forming units
After birth, the cells lining the intestinal tract of newborns are exposed to a wide variety of matter and organisms not present in amniotic fluid. Luminal contents have been shown to have the capacity to alter the functioning of the host organism. For instance, noninfectious bacteria are capable of modulating expression of the genes of the intestinal epithelial cells associated with maturation, nutrient absorption, and components of innate protection $(1,2)$. Similarly, food components such as colostrum can facilitate the successful transition of the mam-

Received November 13, 2001; accepted July 31, 2002.

Correspondence: David R. Mack, M.D., Department of Pediatrics, Children's Hospital of Eastern Ontario, 401 Smyth Road, Ottawa, Ontario, Canada, K1H 8L1; e-mail: dmack@cheo.on.ca

DOI: 10.1203/01.PDR.0000041517.15440.F3 malian neonate to extrauterine life (3). Colostrum breast milk is one of the first nutrients newborns are administered. Colostrum is a complex source of nutrients, immune factors, and bioactive substances that enhances immune, endocrine, and metabolic function, in addition to factors that mediate cell growth and/or differentiation of the intestine $(3,4)$. Montagne et al. (5) demonstrated that calves fed a diet containing colostrum increased ileal mucin flow compared with those on control diets containing skim milk or fresh whole cow's milk enriched with lactose. Mucins are complex glycoprotein molecules that are a component of inducible innate defenses produced by intestinal epithelial cells (6). Mucins have a number of biologic functions, including limiting access of enteropathogens to epithelial cells $(2,7,8)$. A number of mucin genes have been described, including MUC3, which is the 
major small intestinal mucin, and MUC2, which is the major secreted mucin of the colon $(9,10)$.

We have discovered a SAA3 isoform secreted at high levels into bovine, equine, and ovine colostrum and at lesser levels into milk $4 \mathrm{~d}$ post parturition (11). SAA proteins are traditionally referred to in relationship to their cytokine-induced hepatic production and in relationship to their increased blood concentration during infection and/or inflammation, but their true function remains largely unknown (12). Extrahepatic expression of SAA isoforms has been demonstrated in a variety of tissues. In most mammals, SAA3 appears to be the predominant SAA isoform expressed extrahepatically (13-16). In humans, the four members of the SAA protein gene family are clustered on human chromosome 11p15.1 and predicted sizes of the proteins are $12-19 \mathrm{kD}$ (17). To date, human SAA3 mRNA has not been detected (18).

$N$-terminal sequencing of M-SAA3 has revealed a unique four-amino-acid motif (TFLK), contained within the first eight amino acid residues, that is conserved in the three mammalian species studied (11). This sequence has not been reported to be present in any of the hepatically derived serum amyloid A (A-SAA) isoforms, and M-SAA3 has not been detected in blood (11). Because colostrum has been reported to increase ileal mucin flow, we examined whether bovine-based M-SAA3 10-mer peptides containing the conserved TFLK peptide motif were capable of inducing MUC3 mucin expression and the impact of modulation on the capability of an intestinal pathogen to adhere to epithelial cells using an in vitro bioassay.

\section{MATERIALS AND METHODS}

Cell growth conditions. HT29 cells (American Type Culture Collection, Rockville, MD, U.S.A.) were grown in McCoy's 5a medium (Modified, Invitrogen, Carlsbad, CA, U.S.A.). Some HT29 cells were progressively transferred from the original glucose-containing cell culture medium to a glucose-free, 5-mM galactose-containing McCoy's 5a culture medium to increase MUC3 mRNA expression and reduce MUC2 mRNA expression (19). Culture medium was supplemented with $10 \%$ heat-inactivated qualified FBS (Invitrogen) and an antibiotic/ antimycotic mixture $(100 \mathrm{U} / \mathrm{mL}$ penicillin $\mathrm{G}, 100 \mathrm{mg} / \mathrm{mL}$ streptomycin sulfate, and $0.25 \mathrm{mg} / \mathrm{mL}$ amphotericin B, Invitrogen). Cell cultures were grown at $37^{\circ} \mathrm{C}$ in a humidified atmosphere with $5 \% \mathrm{CO}_{2}$. Cells were passaged after washing with Earle's balanced salt solution (Invitrogen) using trypsin-EDTA (Invitrogen).

Peptide synthesis. Peptides (Table 1) were synthesized by using solid-phase methods on a Model 430A synthesizer (Ap- plied Biosystems, Foster City, CA, U.S.A.) by Sam Sanderson, Eppley Institute for Research in Cancer and Allied Sciences, University of Nebraska Medical Center, Omaha, NE. Syntheses were performed on a $0.25-\mathrm{mmol}$ scale on a Wang resin using the $N$-(9-fluoenyl)methoxycarbonyl (Fmoc) synthetic scheme. Peptides were purified by analytical and preparative HPLC columns packed with $\mathrm{C}_{18}$-bonded silica gel and were characterized by amino acid compositional analysis and mass spectrometry. The details of these methods have been previously reported (20).

Alteration in mucin mRNA expression. HT29 cells were grown to $85 \%$ confluence in culture flasks in either glucosecontaining culture medium or glucose-free, galactosecontaining medium. Synthetic peptides were added to culture medium for a 1 -h incubation period at $37^{\circ} \mathrm{C}$ in a humidified atmosphere with $5 \% \mathrm{CO}_{2}$.

Total RNA was isolated from the cells using the guanidine isothiocyanate-cesium chloride cushion ultracentrifugation technique as previously described but with modifications to minimize mRNA shearing $(19,21)$. RNA was stored in $0.3 \mathrm{M}$ sodium acetate, $\mathrm{pH} 6.0$, with 2.5 volumes of ethanol at $-70^{\circ} \mathrm{C}$. Northern blots were performed by subjecting $20 \mu \mathrm{g}$ of RNA to electrophoresis on $1.2 \%$ agarose gels containing $0.66 \mathrm{M}$ formaldehyde and ethidium bromide to visualize RNA. Transfer of RNA to nitrocellulose membranes was accomplished via capillary blotting. Probe hybridization was carried out at $42^{\circ} \mathrm{C}$ for $18 \mathrm{~h}$ using either a cDNA probe to the tandem repeat region of MUC2 (clone SMUC41) or MUC3 (clone SIB124), kindly provided by Drs. James Gum and Young Kim (19). Signals corresponding to MUC2 or MUC3 were detected by PhosphorImager autoradiography (Molecular Dynamics, Sunnyvale, CA, U.S.A.) and were quantified by area integration using ImageQuant software (version 3.3; Molecular Dynamics). Amounts of 28S rRNA loaded onto agarose/formaldehyde gels used for Northern blots were measured using a Computing Densitometer with ImageQuant software (version 3.3; Molecular Dynamics) from photographic negatives (Type 665 film; Polaroid, Cambridge, MA, U.S.A.) of these gels taken under UV light. Comparison of changes in mucin expression could then be assessed relative to 28S rRNA levels.

Bacteria and growth conditions. EPEC strain E2348/69 (serotype O127:H6) was originally isolated during an outbreak of infantile diarrhea (22) and kindly provided by Dr. James Kaper, Center for Vaccine Development, Baltimore, MD. This EPEC strain was maintained on trypticase soy agar slants (Becton-Dickenson Microbiology Systems, Cockeysville, MD) at $4^{\circ} \mathrm{C}$. Stock cultures of Lactobacillus rhamnosus strain GG

Table 1. Synthetic peptide sequences

\begin{tabular}{|c|c|c|c|}
\hline Peptide & Name & Peptide sequence & Description \\
\hline 1 & Bovine N-terminal peptide & MWGTFLKEAG & Bovine M-SAA3 N-terminal 10-mer peptide \\
\hline 2 & Lapine N-terminal peptide & WLTTFLKEAG & Lapine SAA3 N-terminal 10-mer peptide \\
\hline 3 & Conserved motif & TFLK & $\begin{array}{l}\text { Conserved 4-mer peptide motif found in all M-SAA3 of bovine, ovine and } \\
\text { equine sources }\end{array}$ \\
\hline 4 & Limited scramble & MWGLTKFEAG & Bovine M-SAA3 N-terminal 10-mer peptide with the TFLK motif scrambled \\
\hline 5 & Total scramble & GKFAWEGMTL & Bovine M-SAA3 N-terminal 10-mer peptide all scrambled \\
\hline 6 & C-terminal & DDAQRGPQA & Bovine M-SAA3 C-terminal 10-mer peptide conserved in all SAA \\
\hline
\end{tabular}


(American Type Culture Collection 53103) originally isolated from stool specimens of healthy humans (23) were maintained on MRS agar (Difco Laboratories, Detroit, MI, U.S.A.) at $4^{\circ} \mathrm{C}$. This Lactobacillus strain is one of a number of Lactobacillus species that has been previously been demonstrated to colonize human intestinal tract after oral administration (24).

Bacteria were grown overnight at $37^{\circ} \mathrm{C}$ in static nonaerated Penassay broth (EPEC; Difco) or MRS broth (L. rhamnosus; Difco). Bacteria were harvested by centrifugation at $2500 \times g$ for $15 \mathrm{~min}$ at $20^{\circ} \mathrm{C}$ in a GPR centrifuge (Beckman Coulter, Inc., Fullerton, CA). After two washes in sterile, $\mathrm{pH} 7.4$ Dulbecco's PBS (Invitrogen) at $25^{\circ} \mathrm{C}$, bacteria were resuspended in PBS, pH7.4. Quantification of bacterial suspensions was determined using a standard curve of CFU on MacConkey agar (Difco) or MRS agar (Difco) relative to visible absorbance $(600 \mathrm{~nm}$; Spectronic Genesys 5 spectrophotometer, Rochester, NY, U.S.A.).

In vitro EPEC inhibition assay. Alterations in the adherence to HT29 cells, grown to enhance MUC3 expression by growing in a galactose-containing cell culture medium, was determined using an in vitro assay previously described (7). Briefly, HT29 cells were suspended in antibiotic-free culture medium and transferred to individual wells of a 12-well polystyrene tray (Fisher Scientific, Pittsburgh, PA, U.S.A.). Cells were grown to near confluence and washed (three times) with sterile, $37^{\circ} \mathrm{C}$ Hanks' balanced salt solution (Invitrogen) to remove culture medium and nonattached cells. Wells received either $10^{9} \mathrm{CFU}$ of L. rhamnosus strain GG or 10-mer peptides based on bovine $N$-terminal M-SAA3 that contained intact TFLK-motif (peptide 1, Table 1) or with the TFLK-motif scrambled (peptide 4, Table 1) at a concentration of $50 \mu \mathrm{g} / \mathrm{mL}$ cell culture medium. The peptides or bacteria were added $1 \mathrm{~h}$ before the addition of $10^{6} \mathrm{CFU}$ of EPEC E2348/69. After a 3-h incubation at $37^{\circ} \mathrm{C}$, cells were washed four times with Dulbecco's PBS $\left(\mathrm{pH} 7.4,37^{\circ} \mathrm{C}\right)$ to remove nonadherent bacteria. Cells with adherent bacteria were released from polystyrene wells using $0.1 \mathrm{~mL}$ of trypsin-EDTA. After $10 \mathrm{~min}$, ice-cold sterile PBS was added to each well and the well contents were agitated to dissociate epithelial cells. Serial dilutions of adherent bacteria were plated onto MacConkey agar and incubated overnight at $37^{\circ} \mathrm{C}$ for subsequent quantification by counting CFU. All experiments were run in triplicate.

Statistical methods. Group data were expressed as means \pm SEM (SE). Analyses between multiple groups were determined using one-factor ANOVA with $95 \%$ confidence intervals. Posthoc ANOVA analyses were determined by Fisher's protected least-significant difference using StatView software (version 5.0.1; SAS Institute Inc., Cary, NC, U.S.A.).

\section{RESULTS}

Alteration in MUC3 mRNA expression. Because the small intestine was the likely location where ingested peptides found in colostrum would effect changes, alterations in the expression of MUC3 mucins were evaluated first. As shown in Figure 1, there was a concentration-dependent increase of MUC3 mRNA expression by the enterocytes after the addition of bovine M-SAA3 10 -mer $N$-terminal peptide to a maximum of about
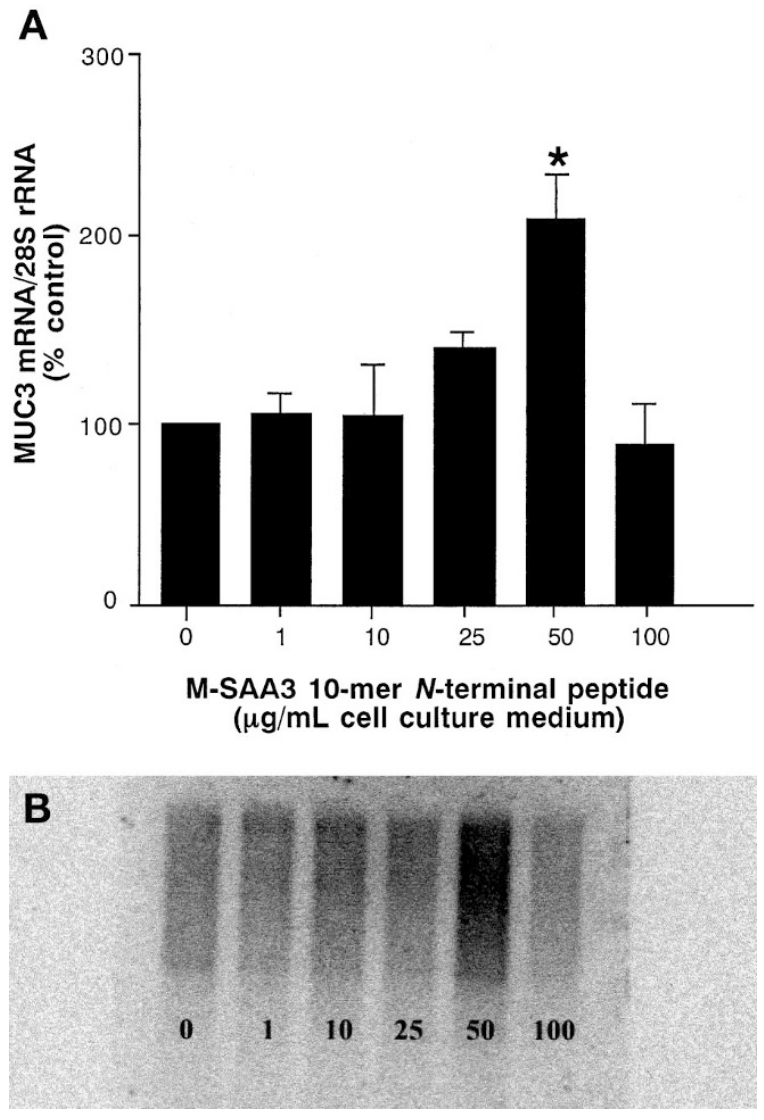

Figure 1. Relative MUC3 mRNA expression levels after incubation of HT29 cells with bovine-based M-SAA3 synthetic peptide (see Table 1 for peptide descriptions). (A) Mean values ( \pm SE) for MUC3 mRNA signal quantified from phosphor screen autoradiographies were normalized relative to the $28 \mathrm{~S}$ rRNA loaded on agarose gels. Results are expressed as a percentage of control values for cells with no synthetic peptide added and are from a minimum of seven separate experiments. ${ }^{*} p<0.05 v s$ other concentrations. $(B)$ Northern blot of one of the experiments with $20 \mu \mathrm{g}$ of total RNA from HT29 cells grown in galactose-containing cell culture medium to enhance MUC3 mRNA expression and incubated with different concentrations of bovine-based M-SAA3 peptides. The blot was hybridized with a MUC3 cDNA probe.

2.5-fold greater than baseline MUC3 mRNA expression at 50 $\mu \mathrm{g} / \mathrm{mL}$ but a decrease in MUC3 expression with the addition of peptides at a concentration of $100 \mu \mathrm{g} / \mathrm{mL}$.

In other experiments, the incubation time of the peptide with the cells was shortened to $30 \mathrm{~min}$ and extended to $90 \mathrm{~min}$. MUC3 mRNA expression was not any greater for the lengthened incubation period.

Comparison of TFLK-containing peptides in modulating MUC3 mRNA expression. Peptides were synthesized based on the deduced $N$-terminal 10-mer sequence reported for rabbit SAA3 (25). As can be seen in Table 1, the carboxyl side of the TFLK motif is the same for the bovine and lapine SAA3, whereas the $N$-terminal side of the motif is not. Additionally, we also tested just the 4-mer TFLK peptide added into culture medium at a concentration of $50 \mu \mathrm{g} / \mathrm{mL}$. After a 30-min incubation period, total RNA was collected for analysis of MUC3 mRNA expression levels. As shown in Figure 2, there was increased MUC3 mRNA expression by HT29 cells incubated with all the various peptides compared with expression of MUC3 mRNA by control HT29 cells without peptides 


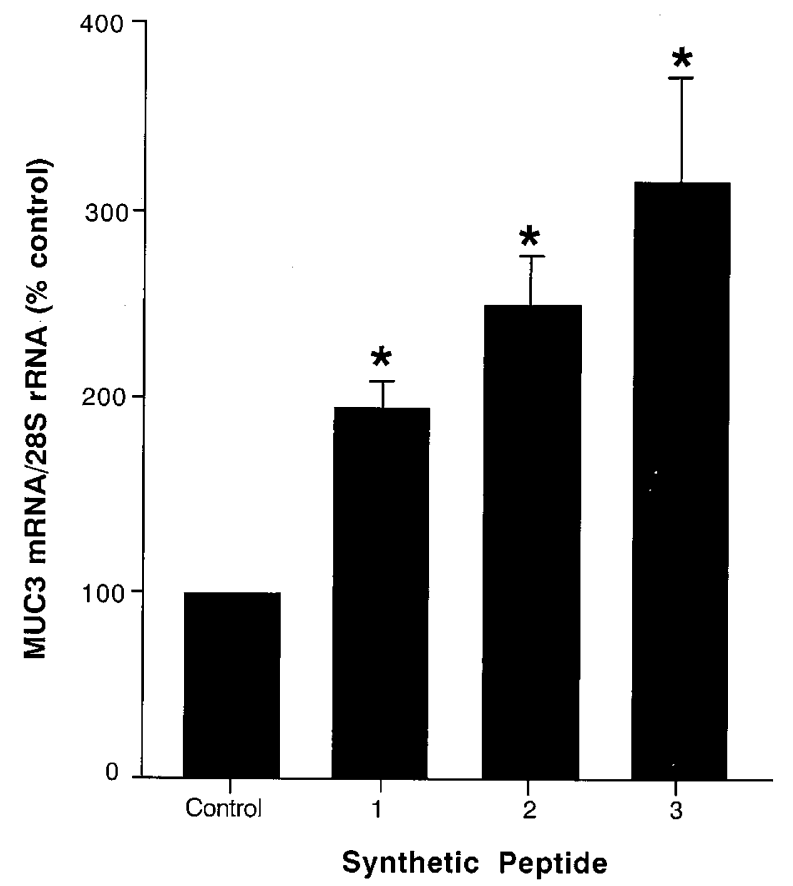

Figure 2. MUC3 mRNA expression levels after incubation of HT29 cells with synthetic peptides containing the TFLK motif. (See Table 1 for peptide descriptions.) Mean values ( \pm SE) are of MUC3 mRNA signal that are normalized to $28 \mathrm{~S}$ rRNA levels loaded onto gels used for Northern blots. Results are expressed as percentage of controls without synthetic peptide added and represent seven separate experiments. ${ }^{*} p<0.05 v s$ controls.

added (ANOVA, $p<0.05$ ). The bovine-based peptides induced approximately a two-fold increase in MUC3 mRNA expression compared with controls. The lapine-based peptides increased expression about 2.5 -fold. Interestingly, the 4-mer TFLK peptide increased MUC3 mRNA mucin expression more than three-fold relative to control levels of MUC3 mRNA expression.

Specificity of conserved M-SAA3 TFLK motif and MUC3 mRNA expression. Various peptides were synthesized and tested to evaluate the specificity of the TFLK motif to effect modulation of intestinal epithelial cell MUC3 mucin gene expression. As shown in Table 1, these included scrambling the four residues of the TFLK motif but keeping the three flanking residues identical (limited scramble) to the bovine-based $\mathrm{N}$ terminal deduced sequence, scrambling all 10 amino acid residues of bovine-based M-SAA3 10-mer peptide (total scramble) and a 10-mer peptide deduced from the C-terminal side of the M-SAA3 protein (C-terminal). Peptides were added at a concentration of $50 \mu \mathrm{g} / \mathrm{mL}$ of cell culture medium for the HT29 cells grown to enhance MUC3 expression in glucosefree, galactose-containing medium. As shown in Figure 3, there was no difference in the MUC3 mRNA expression levels between cells incubated with peptides containing the scrambled TFLK motif, the scrambled 10-mer, the conserved $C$ terminal peptide, and control cells that had not been incubated with any synthetic peptide. Expression levels were all less than cells incubated with the intact 10-mer bovine-based M-SAA3 $(p<0.05)$.

To determine the specificity of the MUC3 mucin gene response, we also evaluated whether MUC2 mRNA expression

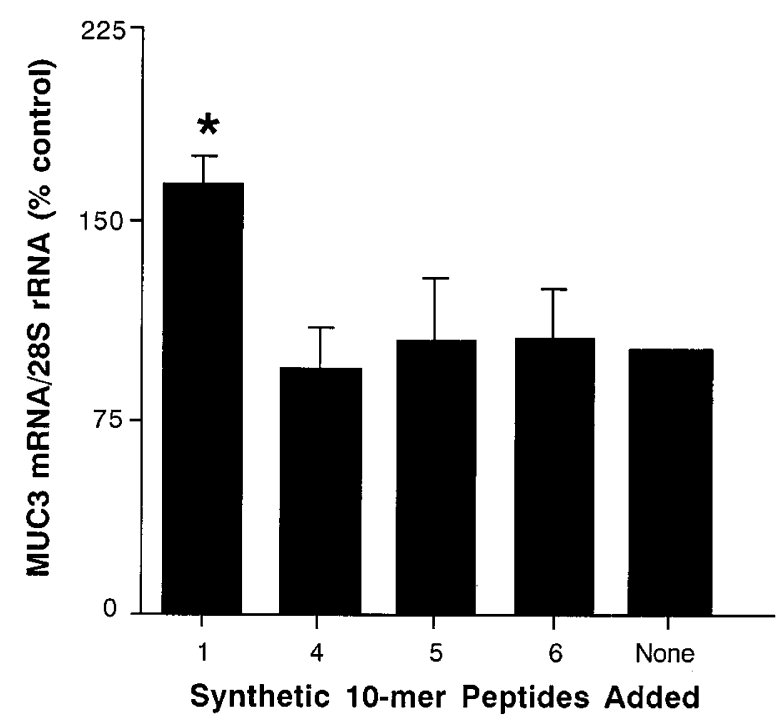

Figure 3. MUC3 mRNA expression levels after incubation of HT29 cells with 10-mer M-SAA3-based peptide sequences. Mean values ( \pm SE) are MUC3 mRNA signal that are normalized to 28S rRNA levels loaded onto gels used for Northern blots. Results are expressed as percentage of controls without synthetic peptide added and represent six separate experiments. ${ }^{*} p<$ $0.05 v s$ other peptides and controls without peptides added.

in HT29 cells grown in glucose-containing cell culture medium was modified by these synthetic peptides. There were no differences in MUC2 mRNA expression levels between control cells and cells incubated with any of the peptides including the 10-mer bovine-based M-SAA3 ( $p>0.05$, data not shown).

Inhibition of EPEC adherence. In experiments using the in vitro adherence assay (Fig. 4), both the addition of M-SAA3based 10-mer peptides containing the intact TFLK motif and probiotic bacteria to the cell culture media of MUC3-producing HT29 cells decreased adherence of EPEC relative to untreated control cells $(p<0.05)$. In contrast, adding a 10-mer peptide without an intact TFLK motif did not alter EPEC adherence to HT29 cells compared with controls $(p>0.05)$.

\section{DISCUSSION}

Colostrum is known to supply both nutrients and agents that can affect growth, development, immunologic, neurologic or epithelial cell function of the gastrointestinal tract (26). In this report, we demonstrate specific alteration in expression of MUC3 mucins by peptides derived from a novel protein isolated from the colostrum of mammals (11). The level of increased expression of mucins is sufficient to inhibit enteropathogen binding in the EPEC adherence bioassay. Our current results confirm previous results showing eukaryotic gene expression may be modified by luminal contents that are normally located in the lumen of the intestinal tract in contact with mucosal epithelial cells such as nonpathogenic prokaryotic organisms (2). We extend these results by showing bioactive peptides that may be present in lumen through ingestion of food products also may affect intestinal epithelial cell gene expression by showing these peptides can also up-regulate MUC3 expression. That small intestinal mucin expression may be up-regulated by multiple mechanisms suggests an important 


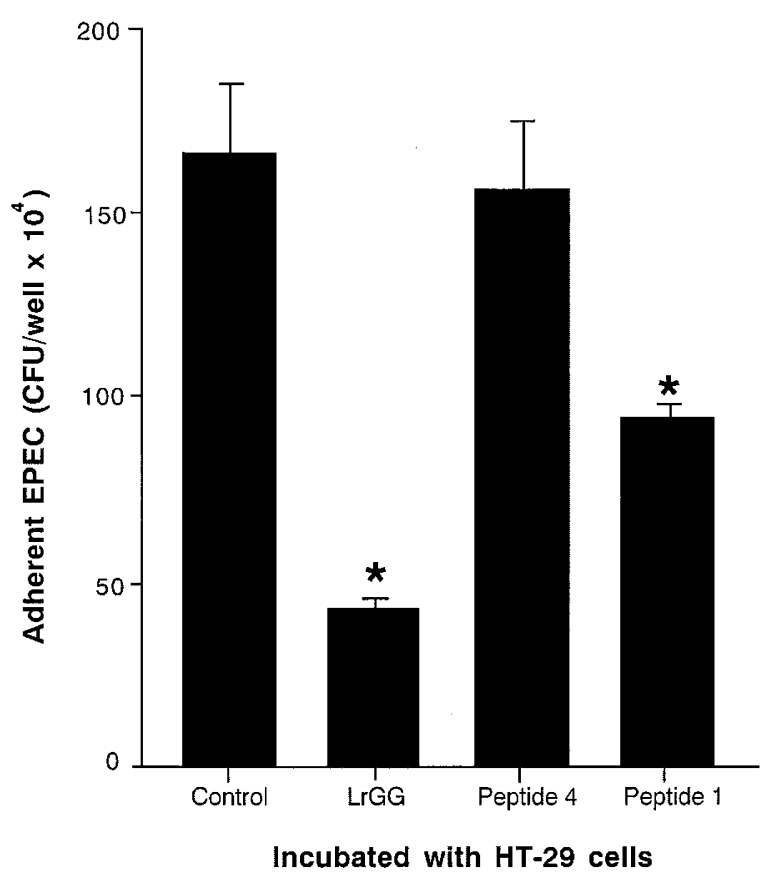

Figure 4. EPEC adherence to HT29 cells. HT29 cells were grown to near confluence in wells of 12-well polystyrene plates with galactose-containing cell culture medium to enhance MUC3 mucin expression. Wells of a 12-well plate received either $10^{9} \mathrm{CFU}$ of L. rhamnosus strain GG, $50 \mu \mathrm{g} / \mathrm{mL}$ of peptide 1 or 4 (see Table 1) or nothing $1 \mathrm{~h}$ before the addition of $10^{6} \mathrm{CFU}$ of EPEC E2348/69. After a 3-h incubation, unbound bacteria were removed and EPEC adherent to HT29 cells were quantified by CFU determinations on MacConkey agar. Results are expressed as mean $\pm \mathrm{SE}$ of at least three experiments run in triplicate. Adherence of EPEC was decreased in wells containing either M-SAA3-based 10-mer peptides or L. rhamnosus strain GG relative to untreated cells (nothing) $(p<0.05$, ANOVA).

role of mucins to the intestinal mucosa. To detect MUC3 expression, a cDNA probe to the tandem repeat region of the molecule was used. Recently, the existence of a second MUC3 gene has been proposed $(27,28)$. Both human MUC3 genes, now called MUC3A and MUC3B, show such significant similarity that the cDNA probe used in these studies would recognize transcripts from both genes (27).

For these studies, we used the HT29 cell line. Although MUC3 mucin mRNA expression has been demonstrated in a number of cell lines, the MUC3 expression levels are low in those cell lines in comparison with MUC2 expression levels (29). The HT29 cell line is capable of undergoing reversible differentiation with the expression of enterocyte-like phenotype in a glucose-free, galactose-containing medium (30-32). In addition, when HT29 cells are transferred from glucosecontaining to glucose-free, galactose-containing cell culture medium, there is up-regulation of MUC3 with concomitant reduction in MUC2 mRNA expression (19). This finding would be consistent with the conclusion HT29 cells differentiate into small intestinal-like cells when transferred to a galactose-containing medium. Thus, these cells are useful for studies on selective intestinal expression of MUC2 and MUC3 mucins.

The finding that M-SAA3 could alter mucin expression was specific to the major small intestinal mucin, namely MUC3 mucins. That is, we did not observe alterations in transcrip- tional expression of MUC2 mucin, the major secreted mucin of the large bowel (33). This finding is important because different Lactobacillus strains have been shown to up-regulate both MUC2 and MUC3 mucin gene expression (2). In addition, co-culture of selective probiotic bacteria with EPEC, like co-culture of M-SAA3 peptides with EPEC, leads to inhibition of EPEC adherence to mucin-producing epithelial cells (2). Specific receptors for various other enteropathogens and viruses have been identified on mucin molecules (8). Exogenous mucins added to cell culture media of non-mucin-producing epithelial cells limits EPEC epithelial cell adherence in a quantitative manner $(2,7)$. Mucins have been shown to be the major component of meconium of newborns that are responsible for inhibition of epithelial cell adhesion of a bacterium that causes neonatal sepsis and meningitis, namely Sfimbriated Escherichia coli (34). Prevention of access to the underlying intestinal epithelial cell can be a process critical in the postparturition period to the newborn infant as their acquired immune system is relatively ineffective.

In the current study, we evaluated bovine-based M-SAA3 peptides, but the mammary-associated amyloid protein has been isolated from bovine and other mammalian species colostrum and milk. To date, human SAA3 mRNA has not been detected in various tissues tested (liver, synovium, fat, lung) (18). Sequence analysis has shown a single base insertion at codon 31 leading to a stop signal at codon 43 (18). Taken together, current opinion is that human SAA3 is a pseudogene, although efforts are underway to determine whether there is expression in tissues other than those previously examined. Interestingly, the 4-mer TFLK and the lapine-based M-SAA3 10-mer peptides were more effective than bovine-based MSAA3 10-mer peptides in up-regulation of MUC3 expression (Fig. 2). Lapine-based M-SAA3 differs from bovine-based M-SAA3 in the flanking amino acid residues on the carboxyl side of the TFLK motif showing flanking residues modify the activity of induction of MUC3 expression.

Bovine-based M-SAA3 is expressed in bovine mammary epithelial cells (11). Extrahepatic expression of SAA3 has been demonstrated in the intestines of mice. In the spontaneously developing colitis of IL-2 deficient ( $-/-)$ and IL-2 deficient $(+/-)$ mice, de Villiers et al. (35) showed that there is increased mRNA SAA3 expression in the lamina propria cells of their intestines. In vitro studies have shown intestinal epithelial cells are capable of secretion of SAA in response to specific sets of cytokines and to glucocorticoids (36). Taken together with the effects on mucin expression, it suggests that intestinal expression of SAA3 may have a role in attempting to limit a chronic inflammatory responses in addition to a role in limiting access of enteropathogens.

In summary, M-SAA3-based peptides increased MUC3 mRNA expression but did not increase transcription of the major colonic mucin, MUC2 mucin. The conserved TFLKmotif was found to be active in modulation of MUC3 mRNA expression. Modulation of the expression of small intestinal mucins by bioactive peptides from colostrum may be a mechanism whereby innate protective mechanisms of newborns are quickly enhanced after ingestion of colostrums by newborns 
and thereby prevent access of enteropathogens to the intestinal mucosa of newborns after parturition.

\section{REFERENCES}

1. Hooper LV, Wong MH, Thelin A, Hansson L, Falk P, Gordon JI 2001 Molecula analysis of commensal host-microbial relationships in the intestine. Nature 291:881884

2. Mack DR, Michail S, Wei S, McDougall L, Hollingsworth MA 1999 Probiotics inhibit enteropathogenic $E$. coli adherence in vitro by inducing intestinal mucin gene expression. Am J Physiol 276:G941-G950

3. Grosvenor CE, Picciano MF, Baumrucker CR 1993 Colostrum and milk-derived peptide growth factors for the treatment of gastrointestinal disorders. Am J Clin Nutr 14:710-728

4. Kodolvsky O 1989 Search for a role of milk-borne biologically active peptides for the suckling. J Nutr 199:1543-1551

5. Montagne L, Toullec R, Lalles JP 1999 Calf intestinal mucin: isolation partial characterization, and measurement in ileal digesta with enzyme-linked immunosorbent assay. J Dairy Sci 83:507-517

6. Hecht G 1999 Innate mechanisms of epithelial host defense: spotlight on intestine. Am J Physiol 277:C351-C358

7. Smith CJ, Kaper JB, Mack DR 1995 Intestinal mucin inhibits adhesion of human enteropathogenic Escherichia coli to HEp-2 cells. J Pediatr Gastroenterol Nutr 21:269-276

8. Dai D, Nanthkumar N, Newburg S, Walker WA 2000 Role of oligosaccharides and glycoconjugates in intestinal host defense. J Pediatr Gastroenterol Nutr 30:S23-S33

9. Chang SK, Dohrman AF, Basbaum CB, Ho SB, Tsuda T, Toribara NW, Gum JR, Kim YS 1994 Localization of mucin (MUC2 and MUC3) messenger RNA and peptide expression in human normal intestine and colon cancer. Gastroenterology 107:28-36

10. Weiss AA, Babyasky MW, Ogata S, Chen A, Itzkowitz SH 1996 Expression of MUC2 and MUC3 mRNA in human normal, malignant, and inflammatory intestinal tissues. J Histochem Cytochem 44:1161-1166

11. McDonald TL, Larson MA, Mack DR, Weber A 2001 Elevated extrahepatic expression and secretion of mammary-associated serum amyloid A 3 (M-SAA3) into colostrum. Vet Immunol Immunopathol 83:205-213

12. Jensen LE, Whitehead AS 1998 Regulation of serum amyloid A protein expression during acute-phase response. Biochem J 334:489-503

13. Benditt ER, Meek RL 1989 Expression of the third member of the serum amyloid A gene family in mouse adipocytes. J Exp Med 169:1841-1846

14. Ramadori G, Sipe JD, Colten HR 1985 Expression and regulation of the murine serum amyloid A (SAA) gene in extrahepatic sites. J Immunol 135:3645-3647

15. Meek RL, Eriksen N, Benditt EP 1992 Murine serum amyloid A3 is a high density apolipoprotein and is secreted by macrophages. Proc Natl Acad Sci U S A 89:79497952

16. Marhung G, Hackett B, Dowton SB 1997 Serum amyloid gene expression in rabbit, mink and mouse. Clin Exp Immnol 107:425-434

17. Sellar GC, Oghene K, Boyle S, Bickmore WA, Whitehead AS 1994 Organization of the region encompassing the human amyloid A (SAA) gene family on chromosome 11p15.1. Genomics 23:492-495

18. Kluve-Beckerman B, Drumm ML, Benson MD 1991 Nonexpression of the human serum amyloid A three (SAA3) gene. DNA Cell Biol 10:651-661

19. Mack DR, Hollingsworth MA 1994 Alteration in expression of MUC2 and MUC3 mRNA levels in HT29 colonic carcinoma cells. Biochem Biophys Res Comm 199:1012-1018
20. Sanderson SD, Kirnarsky L, Sherman SA, Ember JA, Finch AM, Taylor SM 1994 Decapeptide agonists of human C5a anaphylatoxin: the relationship between conformation and spasmogenic and platelet aggregatory activities. J Med Chem 37:31713180

21. Debailleul V, Laine A, Huet G, Mathon P, d'Hooghe MC, Aubert JP, Porchet N 1998 Human mucin genes MUC2, MUC3, MUC4, MUC5AC, MUC5B, and MUC6 express stable and extremely large mRNAs and exhibit a variable length polymorphism. J Biol Chem 273;881-890

22. Levine MM, Nataro JP, Karch H, Baldini MM, Kaper JB, Black RE, Clements ML, O'Brien AD 1985 The diarrheal response of humans to some classic serotypes of enteropathogenic Escherichia coli is dependent on a plasmid encoding an enteroadhesive factor. J Infect Dis 152:550-559

23. Gorbach SL.1996 The discovery of Lactobacillus GG. Nutr Today 31:2S-4S

24. Saxelin M, Elo S, Salminen S 1991 Dose response colonization of feces after oral administration of Lactobacillus casei strain GG. Microbiol Ecol Health Dis 4:209214

25. Mitchell TI, Coon CI, Brinckerhoff CE 1991 Serum amyloid A (SAA3) produced by rabbit synovial fibroblasts treated with phorbol esters or interleukin1 induces synthesis of collagenase and is neutralized with specific antiserum. J Clin Invest 87:11771185

26. Koldovsky O, Goldman AS 1999 Growth factors and cytokines in milk. In: Ogra PL, Mestecky J, Lamm ME, Strober W, Bienenstock J, McGhee JR (eds) Mucosal Immunology, 2nd ed. Academic Press, San Diego, pp 1523-1530

27. Pratt WS, Crawley S, Hicks J, Ho J, Nash M, Kim YS, Gum JR, Swallow DM 2000 Multiple transcripts of MUC3: evidence for two genes, MUC3A and MUC3B. Biochem Biophys Res Comm 275:916-923

28. Kyo K, Muto T, Nagawa H, Lathrop GM, Nakamura Y 2001 Associations of distinct variants of the intestinal mucin gene MUC3A with ulcerative colitis and Crohn's disease. J Hum Genet 46:5-20

29. Hollingsworth MA, Strawhecker JK, Caffrey TC, Mack DR 1994 Expression of MUC1, MUC2, MUC3, and MUC4 mucin mRNAs in human pancreatic and intestinal tumor cell lines. Int J Cancer 57:198-203

30. Pinto M, Appay MD, Simon-Assmann P, Chevalier G, Dracopoli N, Fogh J, Zweibaum A 1982 Enterocytic differentiation of cultured human colon cancer cells by replacement of glucose by galactose in the medium. Biol Cell 44:193-196

31. Zweibaum A, Pinto M, Chevalier G, Dussaulx E, Triadou N, Lacroix B, Haffen K, Brun JL, Rousset M 1985 Enterocytic differentiation of a subpopulation of the human colon tumor cell line HT-29 selected for growth in sugar-free medium and its inhibition by glucose. J Cell Physiol 122:21-29

32. Mack DR, Cheng PW, Perini F, Wei S, Hollingsworth MA 1998 Altered expression of sialylated carbohydrate antigens in HT29 colonic carcinoma cells. Glycoconj J 15:1155-1163

33. Ho SB, Niehans GA, Lyftogt C, Yan PS, Cherwitz DL, Gum ET, Dahiya R, Kim YS 1993 Heterogeneity of mucin gene expression in normal and neoplastic tissues. Cancer Res 53:641-651

34. Schroten H, Lethen H, Hanisch FG, Plogmann R, Hacker J, Nobis-Bosch, Wahn V 1992 Inhibition of adhesion of S-fimbriated Escherichia coli to epithelial cells by meconium and feces of breast-fed and formula-fed newborns: mucins are the major inhibitory component. J Pediatr Gastroenterol Nutr15:150-158

35. de Villiers WJ, Varilek GW, de Beer FC, Guo JT, Kindy MS 2000 Increased serum amyloid a levels reflect colitis severity and precede amyloid formation in IL-2 knockout mice. Cytokine 12:1337-1347

36. Vreugdenhil ACE, Dentener MA, Snoek AMP, Greve JWM, Buurman WA 1999 Lipopolysaccharide binding protein and serum amyloid A secretion by human intestinal epithelial cells during the acute phase response. J Immunol 163:27922798 